\title{
RESONANCE BASED MICROMECHANICAL CANTILEVER FOR GAS SENSING
}

\author{
Subhashini. $S^{1}$ and Vimala Juliet. $A^{2}$ \\ ${ }^{1}$ Research Scholar, Department of Electronics Engineering, Sathyabama University, \\ Chennai, India \\ subhashinivivin@gmail.com \\ ${ }^{2}$ Prof. \& Head, Department of EIE, SRM University, Chennai, India
}

\begin{abstract}
Our world is facing some drastic changes in the climatic conditions due to the heating effect caused by various greenhouse gases. The most harmful gas among them is Carbon dioxide and is increasing at an uncontrolled rate.

This paper aims in finding out the quantity of the major polluting gas carbon dioxide. The gravimetric sensor works by adsorbing the $\mathrm{CO} 2$ molecules on $\mathrm{ZnO}$ sensing layer, which alters the overall mass of the sensor. The mechanical structure is a cantilever, having its own resonant frequency. To selectively adsorb CO2 molecules from the mixture of gaseous molecules, $\mathrm{ZnO}$ at a specific temperature is used. As the gas molecules are adsorbed the mass increases and hence there is a change in resonant frequency. This change in frequency gives the measure of the quantity of CO2 molecules present in that environment. The major expected advantage of this technique would be the repeatability of the sensor that is used. This Quantitative analysis of $\mathrm{CO} 2$ would be helpful for mankind by alerting them about the environment in which they work, by proper conditioning and networking.
\end{abstract}

\section{KEYWORDS}

Micro Cantilever, Resonant Frequency, Sensing Layer

\section{INTRODUCTION}

The term 'greenhouse gases' is used to refer to the gases present in the atmosphere which absorb the radiations and emit them within the thermal infrared range. These gases affect the temperature of the earth significantly, thus the "greenhouse effect" is the heating of the Earth due to the presence of greenhouse gases. The most prominent greenhouse gases in the Earth's atmosphere are water vapor, carbon dioxide, methane, nitrous oxide, ozone and CFCs.

The most harmful gases among them is Carbon dioxide, as its content is increasing in the atmosphere day by day. Carbon dioxide is produced prominently by the respiration of animals, combustion of fossil fuels and geothermal processes, such as eruption of a volcano. Recent estimates reveal, that the concentration of carbon dioxide in the Earth's atmosphere has increased to 387 parts per million by volume. This gas features second in the greenhouse gases list, constituting 9 to 26 percent of greenhouse gases.

Miniaturization has gained enough significance as specified by Moores Law. Hence Microcantilevers are increasingly being used for various measurements. They are comparatively DOI : 10.5121/ijnsa.2013.5210 
inexpensive, show fast response, have high sensitivity and are suitable for mass production using MEMS technology. Hence there is great interest in micro-cantilever based sensors.

This paper deals with an original methodology of measurement of the major polluting gas carbon dioxide. The gravimetric sensor works by adsorbing the $\mathrm{CO} 2$ molecules in $\mathrm{ZnO}$ sensing layer, which alters the overall mass of the sensing element and thereby changing the resonant frequency of the cantilever used. This frequency shift is used to identify the quantity of $\mathrm{CO} 2$ molecules present in the atmosphere. Here a micro-cantilever beam is fabricated using selective coatings on the surface to adsorb $\mathrm{CO} 2$ molecules.

\section{SAMPLE DESIGN AND FABRICATION}

The sensing scheme is that a specific binding induced surface-stress causes bending of the sensing cantilevers. Present research integrates the $\mathrm{SiO} 2$ cantilever with sensing Layer for the measurement of $\mathrm{CO} 2$. The appearance formed would be as shown below in Fig.1
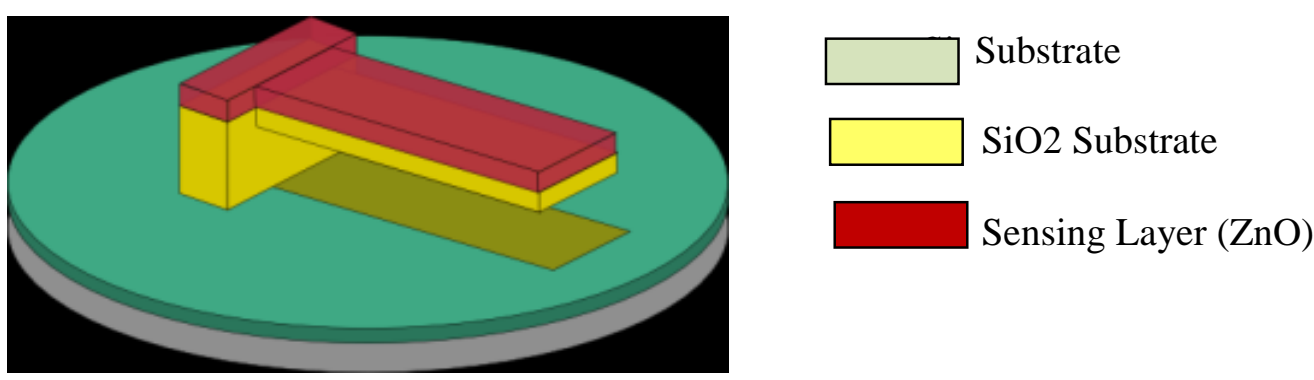

Fig. 1: 3-D Image Of An Integrated Cantilever

\subsection{Theory}

Micro cantilever is a widely used component in micro system devices. It finds wide range of applications in different fields such as biomedical, consumer products due to its flexibility and versatility. A cantilever is type of beam which is supported and constrained at only one end. Few examples of cantilever include diving board, aircraft wings, balconies of buildings etc.

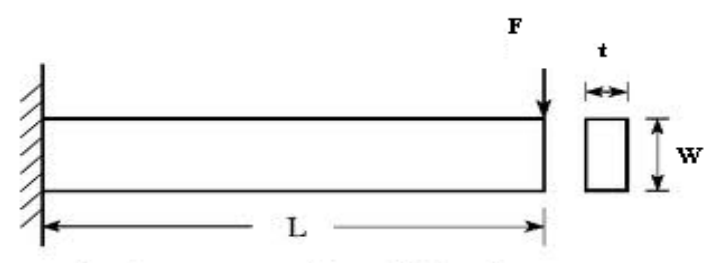

Fig. 2: Simple Cantilever Beam.

Cantilevers come in all sizes. MEMS cantilevers can be as thin as a few nanometers with lengths that range from a few microns to several hundred microns.

Two equations are used to understand the behavior of the MEMS cantilever. The first is the one relating the maximum displacement to the applied force as given below: 


$$
w_{\max }=-\frac{4 L^{3}}{W t^{3}}
$$

Where $\mathrm{w}_{\max }-$ maximum deflection $(\mathrm{m})$

$\mathrm{L}$ - Beam Length (m)

$\mathrm{W}$ - Cantilever Width (m)

$\mathrm{t}$ - Cantilever Thickness (m)

The second is the formula relating the cantilever spring constant $\mathrm{K}$ to the cantilever's dimensions and material constants.

$$
K=\frac{E W \iota^{3}}{4 L^{3}}
$$

Where $\mathrm{F}$ - Force (in N)

$\mathrm{W}$ - Cantilever width (in $\mathrm{m}$ )

By Harmonic oscillator formula,

$$
\omega_{0}-\sqrt{\frac{K}{m}}
$$

Where K-Spring Constant

$\mathrm{m}$ - Mass (in $\mathrm{Kg}$ )

$\omega_{0}$-Cantilever resonance Frequency (in $\mathrm{Hz}$ )

Change in force applied to a cantilever can shift the resonance frequency. The frequency shift can be measured with exquisite frequency accuracy using heterodyne techniques and is the basis of ac-coupled cantilever sensor.

The mass sensitivity $(\mathrm{Sm})$ of a cantilever is defined as the change in frequency divided by the mass load. It can be experimentally calculated by the following equation

Where Sm - Mass sensitivity

$$
S_{m}=\frac{\Delta f}{\Delta m}
$$

$$
\begin{aligned}
& \mathrm{f} \text { - Change in frequency } \\
& \mathrm{m} \text { - Mass load. }
\end{aligned}
$$

\subsection{Cantilever Resonance Frequency Measurement for Chemical Gas Sensors}

The principle used in this type of sensors is to literally catch gas molecules and to weigh them by measuring the shift in resonance frequency. The chemical sensor consists of two key components: a sensitive layer and the transducer (the cantilever). The sensing layer is the critical component and responsible for selectively capturing the $\mathrm{CO} 2$ gas molecules and the cantilever which acts as the transducer converts the mass into a dynamic shift in the resonant frequency. The Molecular weight of $\mathrm{CO} 2$ is $44 \mathrm{~g} / \mathrm{mol}$. The mass change is detected by measuring resonance frequency shifts while actuating the cantilever (dynamic mode). The additional mass load on the cantilever results 
in a decrease of the resonance frequency, which is detected. The simulation was carried out using Intellisuite software and the results are graphically represented in Fig. 3.

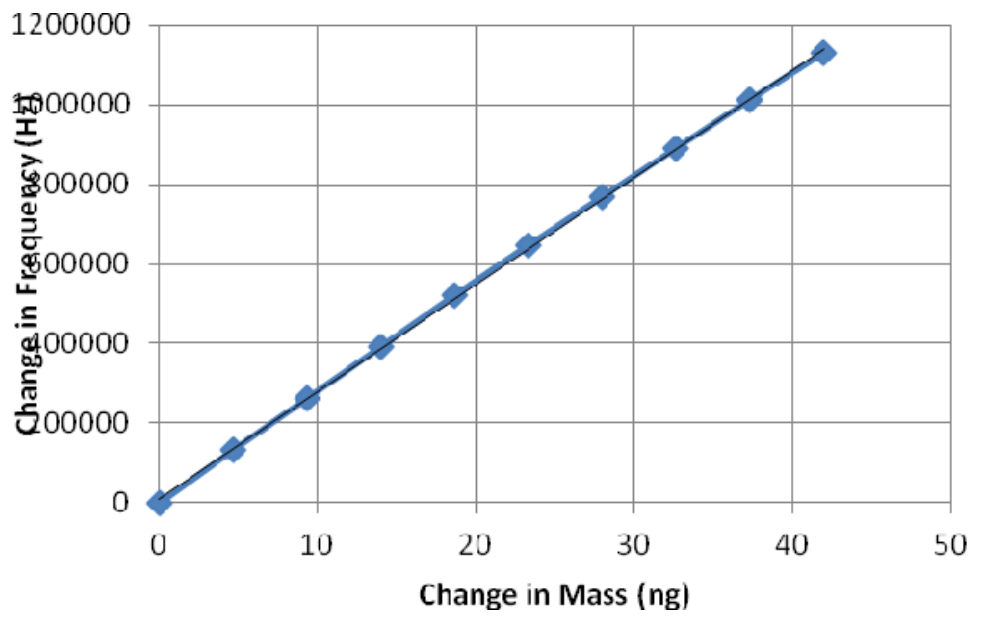

Fig. 3: $m$ to $f$

It is observed that as the change in mass increases there is a corresponding increase in change of frequency. We can hereby calculate the quantity of gas present in that environment from the resonant frequency we obtain. The frequency is related to mass by

$$
\mathrm{f}=\frac{1}{2 \pi} \sqrt{\frac{k}{m}}
$$

\subsection{Micro-Cantilever Array}

Instead of having individual beams they can be combined as an array as shown in Fig. 4 So as to have a combined response.

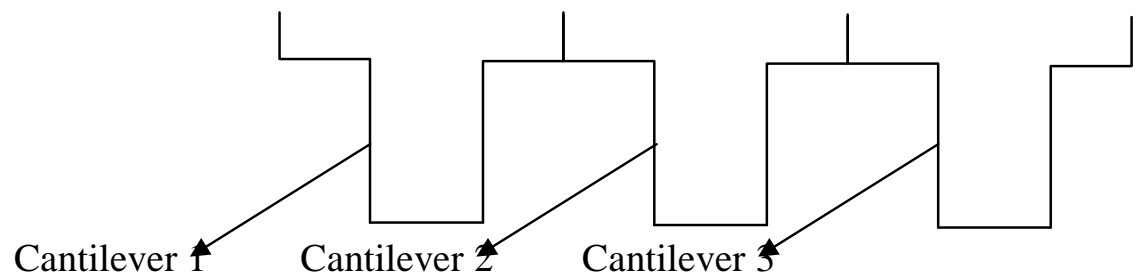

Fig.4: Micro - Cantilever Array

An array of sensors can usually give a better amplified signal which would be of importance and also the selective coating could be varied to give us the quantitative details of $\mathrm{N}$ number of gas molecule detection. 


\subsection{Sensitiveness across the beam}

It would be of significance if we could get the maximum frequency change from the change in mass due to the gas being absorbed. For this reason a micro-cantilever of length: $100 \mu \mathrm{m}$, breadth: $20 \mu \mathrm{m}$ and height $10 \mu \mathrm{m}$ was considered.

The sensitive coatings of length $20 \mu \mathrm{m}$ and thickness of $0.1 \mu \mathrm{m}$ was integrated from the tip of the cantilever to the fixed end and the results were simulated using Intellisuite software and the results are consolidated and graphical represented in Fig. 5

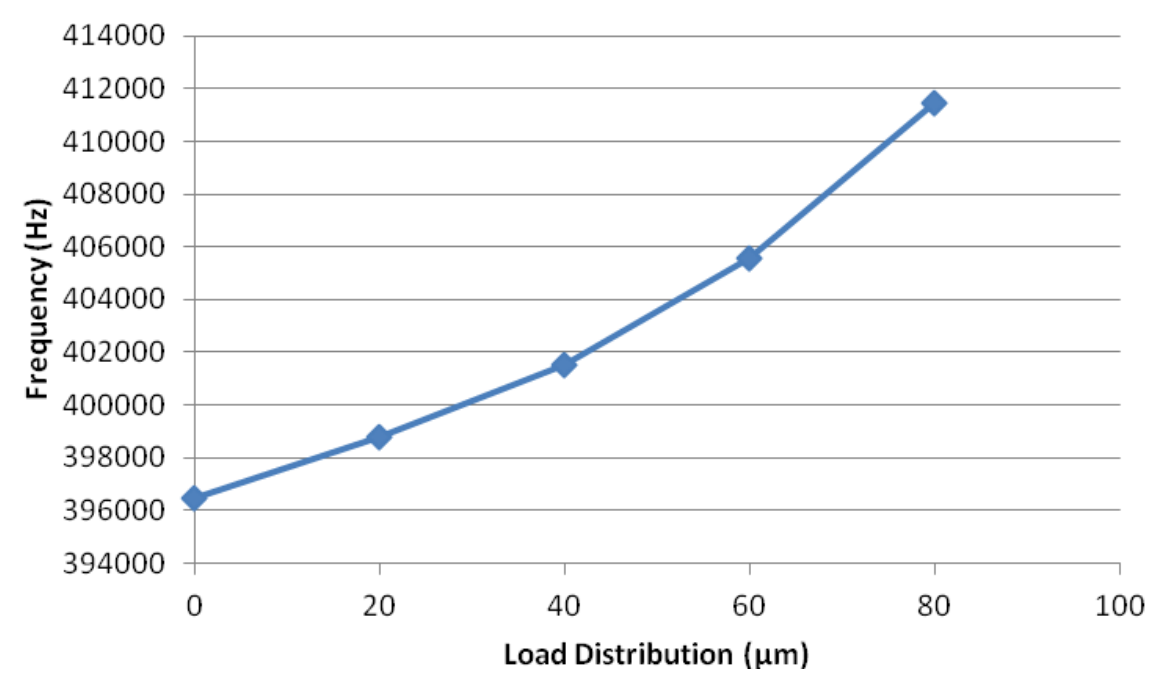

Fig. 5: Load Distribution across the beam

The sensitivity was found to be $4000 / 20^{*} 10^{\wedge}-6$ which is a very efficient one and hence this sensor helps us to identify gas molecules even when the quantity is very as ppb.

\section{Conclusions}

This paper thus brings out the original methodology of measurement of the major polluting gas like carbon dioxide. The absorption of the chemical by a sensitive layer alters the overall mass of the sensing element that varies the resonant frequency i.e an increase in mass leads to a decrease in resonant frequency, this change in frequency gives the mass of $\mathrm{CO} 2$ gas molecules present in the atmosphere. We also observe that when the change in mass in more the resonant frequency change is also more. Finally a micro-cantilever beams sensitivity is observed. This paper could be developed using the same principle to identify various gas molecules. The output could be an electrical signal if this cantilever could be a gate for the FGMOSFET. The obtained voltage could be compared and given to an alarm. 
International Journal of Network Security \& Its Applications (IJNSA), Vol.5, No.2, March 2013

\section{REFERENCES}

[1] H.S.Liao, K.Y. Huang, E.T. Hwu, C.S. Chang, (2010) "Resonance Enhaanced Micromechanical Cantilever for mass sensing", , IEEE/ASME International Conference on Advanced intelligent Mechatronics, Canada.

[2] Alexis Madrigal (2008) "New CO2 Capturing Material Could Make Plants Cleaner", Science Daily Feb. 14.

[3] E. S. Snow, F. K. Perkins, E. J. Houser, S. C. Badescu, and T. L. Reinecke (2005) “ Chemical detection with a single-walled carbon nanotube capacitor" Science, vol. 307, no. 5717, pp. 1942 1945.

[4] S. J. Ippolito, A. Ponzoni, K. Kalantar-Zadeh, W. Wlodarski, E. Comini, G. Faglia, and G. Sberveglieri, (2006) "Layered $\mathrm{WO} 3 / \mathrm{ZnO} / 36$. LiTaO3 SAW gas sensor sensitive towards ethanol vapour and humidity”, Sens. Actuators B, Chem., vol. 117, no. 2, pp. 442-450.

[5] D. Then, A. Vidic, and C. Ziegler, (2006) "A highly sensitive self-oscillating cantilever array for the quantitative and qualitative analysis of organic vapor mixtures," Sens. Actuators B, Chem., vol. 117, no. 1 , pp. 1-9.

[6] K. Zinoviev, C. Dominguez, J. A. Plaza, V. J. C. Busto, and L. M. Lechuga,(2006) "A novel optical waveguide microcantilever sensor for the detection of nanomechanical forces," J. Lightw. Technol., vol. 24, no. 5, pp. 2132-2138.

[7] N. V. Lavrik, M. J. Sepaniak, and P. G. Datskos, (2004) "Cantilever transducers as a platform for chemical and biological sensors," Rev. Sci. Instrum., vol. 75, no. 7, pp. 2229-2253.

[8] U. Schlecht, K. Balasubramanian, M. Burghard, and K. Kern, (2007) "Electrochemically decorated carbon nanotubes for hydrogen sensing," Applied Surface Science, vol. 253, pp. 8394-8397.

[9] M. Wang and Y. Feng, (2007) "Palladium-silver thin film for hydrogen sensing," Sensors and Actuators B, vol. 123, pp. 101-106.

[10] X. M. H. Huang, M. Manolidis, C. J. Seong and J. Hone, (2005) "Nanomechanical hydrogen sensing," Applied Physics Letters, vol. 86, pp. 143104.

[11] I. Voiculescu, M. Zaghloul, A. McGill, (2003)“ Cantilever Gas Sensor”, The Proceedings of the IEEE International Symposium on Circuits and Systems, Bangkok, Thailand, May 25-28.

\section{Authors}

S.Subhashini, completed Masters in Engineering from Annamalai University during November 2001, Currently she is a Research Scholar at Sathyabama University, carrying out research on MEMS based gas sensor. She has a decade of teaching experience in various reputed institutions.

Ms. S. Subhashini is a life member of ISTE and a student member of IEEE.

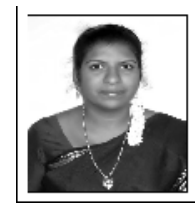

